\title{
FRACASSO ESCOLAR: UM ESTUDO DE CASO DA CRISE EDUCACIONAL CONTEMPORÂNEA EM ARACATI-CE
}

\section{School failure: the contemporary educational crisis at the Adolfo Caminha High School, Aracati-CE}

Renildo Franco da Silva - Faculdade do Vale do Jaguaribe/Brasil

\begin{abstract}
RESUMO: Este trabalho relata a crise educacional contemporânea vivida na EEM Aldolfo Caminha, na cidade de Aracati-CE e sua relação com o fracasso escolar. Tal abordagem se faz necessária, pois o objeto de estudo de acordo com Charlot (2000) tem sido um dos grandes desafios da atualidade, comum em diversas escolas, o que acaba formando um educando cheio de lacunas de aprendizagem por não saber ler ou interpretar situações. Os déficits eclodem nas avaliações externas e no fluxo interno tornando necessário discutir o que leva, não apenas o educando, mas a escola, família e estado, a esse fracasso. A finalidade deste estudo é identificar os fatores que contribuem para o crescimento da crise educacional contemporânea ligada ao fracasso escolar na EEM Adolfo Caminha, Aracati-CE. Este propósito foi realizado mediante a pesquisa de campo no contexto da escola citada que atende, aproximadamente, um mil quinhentos e sessenta e cinco sujeitos, sendo incluída uma amostragem de cinquenta investigados. A análise demonstrou que a escola investigada apresenta fatores muito relevantes que contribuem para o fracasso escolar dos alunos, entre eles destacam-se: a realidade violenta, o uso de drogas, desestruturação familiar e financeira, o uso de metodologias de ensino engessadas, o desinteresse dos alunos e o descompromisso de alguns educadores, as discussões sem objetividade das reuniões de conselho de classe mesmo com a visão inovadora da gestão escolar, culminando com a estrutura educacional defasada oferecida pelo estado.
\end{abstract}

Palavras-chave: Aprendizagem. Educação. Fracasso Escolar.

ABSTRACT: This paper analyzes the contemporary educational crisis experienced at the Adolfo Caminha High Scholl in the city of Aracati-CE and its relationship with school failure. Such an approach is necessary, because school failure has been one of the great challenges of these days, common in schools around the world, which ends up forming a learner full of learning problems for not being able to read or interpret situations. Deficits hatch in external evaluations and internal flow making it necessary to discuss what leads, not only the student, but the school, family, and State, to failure. The purpose of this study is to identify the factors that contribute to the growth of the contemporary educational crisis linked to school failure at the Adolfo Caminha High School, Aracati-CE. This purpose was accomplished through a field research in the context of the mentioned school reaching a universe of fifteen hundred and sixty-five people in a sample of fifty investigated people. The analysis showed that the investigated school has very relevant factors that contribute to the student's school failure, among them: violent reality, drug use, family and financial disorganization, use of old teaching methodologies, student's lack of interest and the disengagement of some educators, council meetings with no objectivity even with the innovative vision of school managers, ending with the old educational structure offered by the State.

Keywords: Learning. Education. School Failure.

Educação, Psicologia e Interfaces, Volume 4, Número 1, p. 76-91, Janeiro/Março, 2020.

ISSN: 2594-5343. DOI: https://doi.org/10.37444/issn-2594-5343.v4i1.220 


\section{INTRODUÇÃO}

Este artigo aborda o crescimento da crise educacional contemporânea ligada ao fracasso escolar. Para isso, partiu da seguinte problemática: Quais os fatores que contribuem para o crescimento da crise educacional contemporânea ligada ao fracasso escolar na EEM Adolfo Caminha, Aracati - CE?

Tal abordagem se justifica devido ao fato do fracasso escolar ser um dos grandes desafios do mundo educacional contemporâneo. É comum escolas de todas as partes do mundo investirem tempo e dinheiro na busca de soluções para os déficits de aprendizagem que eclodem nas avaliações externas e no fluxo interno do ensino médio, o que acaba formando um educando cheio de lacunas de aprendizagem por não saber ler, ou sequer, interpretar um pequeno fragmento que possa ajudá-lo na solução de um problema. Desse modo, faz-se necessário discutir o que leva, não apenas o educando, mas a escola, família e estado, a esse fracasso tão devastador que, por fim, acaba influenciando na construção de uma sociedade próspera, nas relações entre os sujeitos e na conscientização de cidadania.

A investigação é pertinente e relevante por abrir um leque de reflexões quanto aos diversos aspectos que compõem a escola, refletindo também o papel da família, da sociedade e do próprio sujeito-aluno na fase de formação, contribuindo especialmente para um retrato contextualizado da escola estudada, a qual poderá avaliar suas práticas formativas a partir do olhar do pesquisador.

O objetivo geral desse estudo pautou-se em identificar os fatores que contribuem para o crescimento da crise educacional contemporânea ligada ao fracasso escolar na EEM Adolfo Caminha, Aracati - CE. Para isso, elencou-se quatro objetivos específicos com o intuito de desmembrar o objetivo geral para melhor investigar o problema. Foram eles: Analisar o contexto histórico-social dos educandos da instituição pesquisada; Investigar as metodologias de ensino utilizadas pelos educadores da referida escola e sua relação com a aprendizagem significativa; Compreender como ocorre o processo do conselho escolar na escola e sua contribuição para o rendimento dos educandos;

Educação, Psicologia e Interfaces, Volume 4, Número 1, p. 76-91, Janeiro/Março, 2020.

ISSN: 2594-5343. DOI: https://doi.org/10.37444/issn-2594-5343.v4i1.220 
Relacionar a ação docente e discente e suas interrelações no ambiente da sala de aula com o fracasso escolar.

Este propósito foi conseguido mediante a análise de alguns teóricos, tais como, Medeiros (2003), Charlot (2000), Freire (1996), Paula; Tfouni (2009) e Pimenta (2002), bem como de uma pesquisa de campo realizada na EEM Adolfo Caminha, localizada em bairro econômica e socialmente vulnerável da cidade de Aracati, estado do Ceará. Os dados tiveram origem a partir das fontes: o espaço de sala de aula, documentos, o dia a dia nos corredores da escola e reuniões de conselho. Assim, foram utilizadas as técnicas de produção de dados que envolveram a documentação indireta (documentos e bibliografia - caráter documental e análise de observação).

O universo da pesquisa, no âmbito da escola estudada caracterizou-se por: (04) coordenadores, (01) diretor, (60) professores e (1.500) um mil e quinhentos alunos, totalizando (1.565) um mil quinhentos e sessenta e cinco sujeitos.

Do universo foi selecionado um grupo com uma quantidade específica para a pesquisa. Por ser uma pesquisa qualitativa a amostra envolveu apenas alguns sujeitos, distribuídos em: (04) coordenadores, (01) diretor, (15) professores e (30) alunos, totalizando uma amostragem de (50) cinquenta sujeitos.

A pesquisa está dividida em Introdução, com uma abordagem breve da problemática e tema estudados, objetivos e descrição simplificada da metodologia abordada; Discussão teórica, onde se estabelece uma relação, conversação de aspectos iguais ou divergentes entre autores que abordam a temática estudada, dialogada com os objetivos delineados; Materiais e métodos, que traz uma abordagem mais aprofundada de como a pesquisa foi delineada e realizada; Resultados e discussão, onde se discute os resultados apontados pela pesquisa alinhados aos objetivos e problemática traçados; finalizando com as Considerações finais expondo de forma breve, racional, objetiva e clara o resultado da pesquisa, além de retomar pontos principais já discutidos.

\section{MATERIAL E MÉTODO}

Conforme apresentado na introdução a pesquisa foi realizada, após autorização da gestora na EEM Adolfo Caminha - nome fictício para resguardar a identidade da escola -, localizada em bairro econômica e socialmente vulnerável da cidade de Aracati, estado do Ceará. 
O desenho investigativo concentrou-se no enfoque qualitativo visando evidenciar o sociocultural, não concebendo a realidade e o campo de investigação como algo neutro e passivo. Buscou-se representar o mais fielmente possível como as pessoas se sentem, visando saber como e quais são suas crenças, percepções, modos de ver e de entender. Não se visou aplicar dados estatísticos, buscou-se priorizar as percepções de atitude e a subjetividade dos sujeitos interagindo em seu grupo (PIMENTA, 2002).

A pesquisa caracteriza-se como exploratória, pois buscou conhecer melhor o problema que envolveu o fracasso escolar na instituição investigada, visando desenvolver métodos a utilizar em outros estudos, e descritiva (SAMPIERI; FERNÁNDEZCOLLADO; LUCIO, 2006), pois sua pretensão foi representar o mais fielmente possível os contextos socioculturais, as características de uma determinada população. Não é uma investigação de fenômenos apenas individuais, mas aqueles que se fazem grupais, portanto, fez-se necessária a observação participante para conhecer as culturas e suas diversidades, descrevê-las e compreendê-las.

A Produção de dados, não coleta de dados, partiu da ideia de Rey (2005, p. 100) quando observou que a subjetividade social e a individualidade do homem agem como constituintes a partir do outro e pelo outro. Desse modo, não se pôde definir nessa investigação a coleta de dados como uma etapa da pesquisa, "porque realmente dados não se coletam, mas se produzem e, em segundo lugar, porque o dado é inseparável do processo de construção teórica no qual adquire legitimidade" .

Os dados tiveram origem a partir das fontes: o espaço de sala de aula, documentos, o dia a dia nos corredores da escola e reuniões de conselho. Assim, foram utilizadas as técnicas que envolveram a documentação indireta (documentos e bibliografia - caráter documental e análise de observação), todas delineadas de acordo com os objetivos específicos da pesquisa visando responder à problemática da investigação.

De acordo com Sampieri, Fernández-Collado e Lucio (2006, p.562) o processo qualitativo visa "um grupo de pessoas, um evento, uma comunidade etc., sobre a qual se tem de coletar os dados, sem que necessariamente seja representativa do universo ou população que se estuda".

Desse modo, o universo da pesquisa, no âmbito da EEM Adolfo Caminha, seguiu como apresentado na tabela abaixo. 
Tabela 1: População

\begin{tabular}{l|l|l|l|c}
\hline $\begin{array}{c}\text { Coordenador } \\
\text { (a) Pedagógico }\end{array}$ & Direção & Professores & Educandos & Total \\
\hline 04 & 01 & 60 & 1.500 & 1.565 \\
\hline
\end{tabular}

Da população foi selecionado um grupo com uma quantidade específica para a pesquisa. Por ser uma pesquisa qualitativa a amostra envolveu apenas alguns sujeitos, pois, de acordo com Sampieri, Fernández-Collado e Lucio (2006, p. 566), esse tipo de amostra tem como objetivo apresentar

a riqueza, profundidade e qualidade da informação, não a quantidade ou padronização. [...] onde o objetivo é analisar os valores, ritos e significados de um determinado grupo social [...] Com o grupo se efetua um seção: um facilitador ou moderador dirigirá a conversação para que os participantes expressem suas atitudes, valores, medos, expectativas, motivações [...]

Desse modo, a amostra ficou distribuída de acordo com a tabela abaixo:

Tabela 2: Amostra

\begin{tabular}{c|c|c|c|c}
\hline $\begin{array}{c}\text { Coordenador } \\
\text { (a) Pedagógico }\end{array}$ & Direção & Professores & Educandos & Total \\
\hline 04 & 01 & 15 & 30 & 50 \\
\hline
\end{tabular}

A análise dos resultados foi feita através de guias de análise, criadas para fragmentar as informações e depois reorganizá-las com o objetivo de responder ao problema da investigação. Segue, no próximo item, a análise dos resultados evidenciando as informações mais significativas da pesquisa.

\section{RESULTADOS E DISCUSSÃO}

Nesta seção serão apresentados os resultados da pesquisa discutidos a partir dos objetivos interligados ao problema da investigação.

\subsection{Ação docente e discente: interrelações com o fracasso escolar no ambiente de sala de aula}

O fracasso escolar sempre foi motivo de discussão entre gestores educacionais, educadores, pais, alunos etc. Sempre se buscou julgar e identificar os culpados da não aprendizagem exigida em todos os níveis de ensino. Por que o aluno não aprende? A resposta à questão estaria ligada à desestrutura familiar? Ou seria, à falta de preparação 
do professor, que usa uma metodologia fraca e aleatória? O fracasso escolar é um problema atual ou se arrasta pelo sistema educacional há muito tempo? Esse fenômeno vem vigorando na sociedade mundial que aponta o social, a divisão de classes e a falta de perspectiva como seus principais causadores, dispensando um mergulho mais aprofundado em discussões significativas que levem a uma compreensão desse processo, que impede o sujeito-aprendente não apenas de vislumbrar uma profissão, mas de se perceber cidadão de ação.

A realidade educacional atual procura cada vez mais vender um produto. São comuns publicidades, murais com fotografias de alunos espalhados pela cidade entre outros meios de comunicação, oferecendo a imagem dos alunos bem-sucedidos como resultado de uma educação de qualidade. Isso é resultado de um processo aterrorizante que permeia a história da educação, especialmente brasileira, que vem marcada por alunos que desistem de concluir o ensino básico por se sentirem desmotivados aumentando o número de repetentes, marcando o fluxo interno das escolas com altos índices de reprovação. Podemos dizer que a história educacional, seja local ou expandida ao ilimitado mundo da aprendizagem, está associada ao fracasso nas salas de aula, especialmente quando se trata das classes menos favorecidas.

Percebendo em que ponto se encontra o sistema de ensino brasileiro, pode-se dizer, sem medo algum, que alfabetizar não significa necessariamente "aprender", mas saber escrever o nome e ser "empurrado" para o próximo nível, mesmo que cheio de lacunas de conhecimento. É comum encontramos pessoas que podem desmontar um aparelho eletrônico em segundos e remontá-lo em menos tempo ainda, mas que não conseguem ler ou escrever um período simples e muito menos composto, ou resolver uma equação, por mais simples que seja, muito menos refletir seu próprio contexto dentro do contexto do outro.

Pensando estritamente no "fracasso", é impossível identificá-lo como algo com conceito concreto, visto que sua forma de ser percebido está ligada ao mundo genérico das interpretações. O estado, a escola, o gestor, o coordenador pedagógico, o professor e até o próprio aluno pode identificar o fracasso de uma forma muito particular. Como esse educando é percebido num determinado contexto, o que se pretende avaliar, influenciará na decisão de que ele fracassou ou não em seus desafios. Assim, sendo a escola um espaço 
tão importante para a formação dos sujeitos, cabe a ela identificar os fatores que levam esses educandos a fracassarem em sua trajetória acadêmica. Focar numa reflexão aprofundada de seus conceitos, da forma como percebe seu entorno, o que esse entorno lhe oferece como subsídio para uma proposta pedagógica mais firme e clara.

Muitos creditam a ideia de fracasso como uma reprodução de vida dos próprios pais. Ou seja, o aluno é uma mera reprodução histórico-social daqueles que o geraram. Se o pai for pobre seu filho trará tais qualidades. Charlot vai contra essa posição quando diz que "a posição da própria criança se constrói ao longo de sua história e é singular" (2000, p. 21), o que renega o ponto de vista de Bourdieu, estudado por Charlot (2000), por acreditar que a deficiência de aprendizagem se caracteriza como herança familiar, e não se fala aqui de genética, pois isso seria presumir que quem nasce pobre morrerá "pobre". Fala-se de repetir os caminhos utilizados pelos pais, de ver apenas aquela realidade como perspectiva. Como se estivéssemos presos a um ciclo social permanente, onde mesmo que tenhamos contato, ou nos ofereçam um ambiente diferenciado, sempre retornaremos para onde viemos, rejeitaremos em algum momento o que nos foi oferecido. Contrário a isso, Freire (1996), apresenta seu inconformismo em relação a esse condicionamento, vendo a necessidade de ser ver inacabado sem esquecer de suas marcas culturais:

Gosto de ser gente porque, inacabado, sei que sou um ser condicionado, mas, consciente do inacabamento, sei que posso ir mais além dele. Esta é a diferença profunda entre o ser condicionado e o ser determinado. A diferença entre o inacabado que não se sabe como tal e o inacabado que histórica e socialmente alcançou a possibilidade de saber-se inacabado. Gosto de ser gente porque, como tal, percebo afinal que a construção de minha presença no mundo, que não se faz no isolamento, isenta à influência das forças sociais, que não se compreende fora da tensão entre o que herdo geneticamente e o que herdo social, cultural e historicamente, tem muito a ver comigo mesmo. Seria irônico se a consciência de minha presença no mundo não implicasse já o reconhecimento da impossibilidade de minha ausência na construção da própria presença. Não posso me perceber como uma presença no mundo, mas, ao mesmo tempo, explicá-la como resultado de operações absolutamente alheias a mim (FREIRE 1996, p. 23).

Medeiros (2003) aponta uma diversidade de pontos interessantes que reforçam o pensamento do sistema educacional atual. Assim, pode-se dizer que a relação entre maturidade e indisciplina implicam na não aprendizagem e o aluno que não aprende está fadado ao fracasso. Isso implica numa reflexão: seria a maturação elemento essencial da formação humana? Pensar assim levaria muito da responsabilidade do "aprender" ao

Educação, Psicologia e Interfaces, Volume 4, Número 1, p. 76-91, Janeiro/Março, 2020.

ISSN: 2594-5343. DOI: https://doi.org/10.37444/issn-2594-5343.v4i1.220 
próprio sujeito de aprendizagem e o tornaria principal motivador de si mesmo. O que comunga da ideia de Charlot quando aborda o discurso de que o aluno precisa querer aprender para poder, então, aprender. Assim,

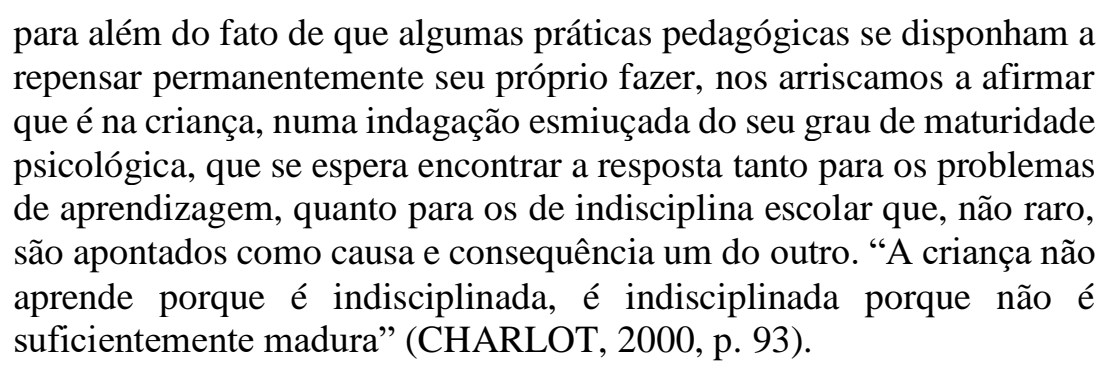

Mas, qual seria o papel da escola? Seu funcionamento, valores, entendimento do que se quer e se propõe a ensinar, o que caracteriza como "fracasso" a colocam como um dos responsáveis pelo desenvolvimento dos alunos junto aos professores, pais e Estado. É a escola, forçada por um mecanismo imposto pelo Estado, que define o que se quer cobrar como habilidade e competência, se um aluno tem mais capacidade que outro etc., não se pautando nas questões sociais locais, mas naquilo que os gestores maiores entendem por problema ou solução. Então, a escola limita o âmbito do fracasso àquilo que, por si, e de acordo com sua visão de desenvolvimento humano, estabeleceu como "sujeito desenvolvido". Muitas vezes, apenas fomenta a justificativa que os alunos de classes sociais mais altas são mais inteligentes porque têm mais condições para obterem livros, cultura etc., enquanto as classes menos abastadas levam à escola crianças que receberão um assistencialismo promotor de inclusão e de uma falsa ideia de desenvolvimento.

De acordo com Paula e Tfouni (2009), baseados nas pesquisas de outras investigações feitas por Angelucci et al. (2004), o fracasso escolar pode ser apresentado em quarto dimensões: Na dimensão psíquica, que parte da ideia de culpa voltada para as crianças e seus pais, um resultado de prejuízos ligados a problemas emocionais gerados no seio familiar. A escola apresenta-se nessa categoria como o espaço que harmoniza, que oferece uma ambiência favorável ao desenvolvimento mergulhado na realidade do aluno. Na dimensão técnica, o professor é tido como o culpado da não aprendizagem pelo uso inadequado de metodologias de ensino fragmentadas, distanciadas da realidade do educando. Já a dimensão da questão institucional reporta à exclusão do aluno pela própria escola. Ou seja, o espaço educacional reproduz e transforma a estrutura social numa

Educação, Psicologia e Interfaces, Volume 4, Número 1, p. 76-91, Janeiro/Março, 2020.

ISSN: 2594-5343. DOI: https://doi.org/10.37444/issn-2594-5343.v4i1.220 
perspectiva de reforçar a diferença de classes com foco no capitalismo, provocando um ambiente de desigualdades. Finalizando, vem a dimensão da questão política que envolve as culturas escolar, popular e suas relações de poder. A escola, nessa dimensão acaba violentando e desvalorizando a identidade cultural do educando quando não reconhece os valores de sua formação cultural popular.

Nessa abordagem, os autores reforçam o pensamento de que a escola ainda não se reconhece como social, ou pelo menos não dá atenção aos sujeitos sociais que recebe em suas salas de aula, enfatizando a luta de classes, a busca por uma posição, que de forma não satisfatória acaba sempre privilegiando aqueles de poder aquisitivo mais elevado, devido à falsa ideia de que são mais competentes por causa de seu nível social.

Nesse momento, aparece a figura do professor, aquele que está diretamente ligado aos processos de Ensino/Aprendizagem dos educandos. Nesse cenário tão cheio de dúvidas, ele passa a ser:

\footnotetext{
um mero instrumento do sistema que indiretamente lhe dita normas por meio de um autor de livro didático, que seleciona os textos que agradam a esse sistema e que, através de um manual, impõe a sua interpretação de acordo com o mesmo sistema. O professor (...) repetindo o que o livro traz impresso, obriga seus alunos à mesma repetição, num processo contínuo de manutenção e reprodução do "status quo" (ASSOLINI, 1999, p. 106).
}

Ou seja, se o aluno não aprender o que fora estabelecido pelo sistema, não poderá ser classificado como "preparado" para a sociedade. Nesse processo, o educador acaba sendo um reprodutor de ideias, de conceitos, avaliando o desempenho dos alunos apenas no que está regrado nos livros ou na concepção avaliativa e individualizada da escola da qual faz parte.

É preciso analisar a individualidade, os caminhos, as metodologias e os preconceitos em relação ao que se pode ou não aprender, ou continuaremos a receber em nossas salas de aula discentes que não aprendem e nunca aprenderão. Passaremos a negar a realidade e o próprio fracasso nas mais diversas dimensões. A partir desse contexto, apresentaremos na próxima seção uma discussão sobre o conselho escolar na EEM Adolfo Caminha.

\subsection{Conselho Escolar e Redimentos: uma busca infindável}


Esta seção tratará de uma descrição reflexiva das reuniões de conselho de classe na escola investigada. Eles são organizados por turmas e ocorrem concomitantes às aulas, ou seja, enquanto o conselho de classe dos primeiros anos acontece, as turmas de segundo e terceiro ano assistem aula. Por esse motivo, os professores que migram entre as turmas acabam deixando atividades nas salas a serem executadas pelos coordenadores.

O formato das reuniões segue a disposição de mesas acopladas com cadeiras em derredor. O professor diretor de turma - PDT, que é escolhido pela gestão para acompanhar a turma e ajudar nos índices durante todo o ano letivo. ou o professor responsável pelas turmas de segundo e terceiro ano, recebe a responsabilidade de apresentar, através de gráficos, os índices da turma e os alunos com dificuldades de aprendizagem daquele período letivo. Os professores discutem sobre as possibilidades de intervenções de acordo com a singularidade dos educandos visando melhorar o fluxo interno e as avaliações externas.

Percebeu-se que é prática dos educadores canalizar as discussões na falta de interesse por parte dos alunos. Para os professores, em sua maioria, as notas baixas e o péssimo rendimento das turmas tem ligação com o desinteresse do estudante, o que muitos concordam ser uma realidade universal e que não há possibilidade de se criar mais nada para sanar esse problema partindo do pressuposto de que todas as tentativas de conduzir os alunos à aprendizagem já foram esgotadas. Figurou-se, nas reuniões, que muitos dos educadores não refletem a necessidade de se avaliar a prática docente numa perspectiva auto reconstrutiva, ou seja, o aluno é o único responsável pelo ato de aprender. Crê-se, na conjuntura atual, que a ideia de protagonismo por parte do aluno estagnou-se em dogmas modernos.

Nesse contexto, a justificativa quanto ao fracasso escolar estava pautada exclusivamente no desinteresse do aluno, pois o professor sempre cumpria suas obrigações. Assim, não se necessita avaliar a ação docente, os processos no "chão da escola", nem o que o aluno não aprendeu.

Ficou claro que a forma como os trabalhos são conduzidos favorecem uma análise superficial dos processos, minimizando as possibilidades de encontrar soluções, bem como formular novos questionamentos quanto ao fracasso escolar. As turmas são numerosas e a defasagem nas diversas disciplinas chega a noventa por cento. Levar um 
conjunto de professores a mergulhar numa autoperseguição de conceitos e metodologias em tão pouco tempo é um prato cheio para más interpretações e o favorecimento de lacunas confundindo caminhos ao invés de nortear ideias que visem esclarecer dúvidas. Não se consegue entender o mecanismo que propulsiona a aprendizagem significativa embasado em vivências sociopolíticas do educando. Muitos tabus e preconceitos em entender o conhecimento bruto do cotidiano do educando como potencialmente válido a novas descobertas intelectuais ainda se enraíza nas salas de aula.

Um dos caminhos apontados por alguns educadores e gestores presentes nas reuniões foi lançar mão da realidade social dos aprendentes no intuito de fazê-lo se perceber utilizando os conteúdos trabalhados em situações-problema vivenciadas na experiência concreta, o que defende a Pedagogia Histórico-Crítica (SAVIANI, 2003), o que, para alguns, pareceu apenas mais trabalho, sem resultado concreto. Percebeu-se que o ato de ensinar se finda na execução de uma profissão desligada das transformações sociais.

Portanto, identificou-se que é necessário que se entenda a prática de formação como algo em processo, inacabado, que precisa ser objeto de diálogo que se perfaz entre a realidade da escola e as características etnográficas daqueles que a produzem, inclusive o professor. Um processo de construção que não seja entendido como desconexões insolúveis, mas uma rede de saberes que se reforça na atuação do professor junto ao núcleo gestor e ao aluno, que analisando as diversas práticas, procuram meios de facilitar o processo educativo e atingir a integralidade do sentido de educar para a vida, amenizando o fracasso escolar que tanto expulsa crianças e jovens do contexto educacional enquanto os condiciona à sobrevivência no mundo capitalista.

\subsection{Contexto histórico social dos educandos da EEM Adolfo Caminha}

\begin{tabular}{|l|l|}
\hline \multicolumn{2}{|c|}{ Categorias conceituais de análise } \\
\hline \multicolumn{2}{|c|}{ Objetivo 1: Analisar o contexto histórico-social dos educandos da instituição } \\
pesquisada
\end{tabular}

Dos dados observados durante a pesquisa, percebeu-se que o educando vem de uma realidade opressora que se respalda na violência, tanto doméstica quanto das ruas, e

Educação, Psicologia e Interfaces, Volume 4, Número 1, p. 76-91, Janeiro/Março, 2020. 
que acaba se estendendo para o espaço escolar, facilitando o uso e venda de drogas. Outro fator que chamou atenção foi a falta de atenção e participação das famílias no dia a dia da escola. Isso acontece devido ao fato de sua desestruturação no sentido de saber quem, de fato, se responsabiliza pelos educandos. Ainda, e não menos preocupante, é a condição econômica dessas famílias. Muitos alunos chegam a receber três refeições em cada turno escolar por falta de alimento em casa, o que ocasiona o seu mau desenvolvimento intelectual.

\subsection{Metodologias de ensino e sua relação com a aprendizagem}

\begin{tabular}{|l|l|}
\hline \multicolumn{2}{|c|}{ Categorias conceituais de análise } \\
\hline \multicolumn{2}{|c|}{ Objetivo 2: Investigar as metodologias de ensino utilizadas pelos educadores da } \\
referida escola e sua relação com a aprendizagem significativa
\end{tabular}

Nesse objetivo, identificou-se que os professores, em sua maioria, ainda utilizam metodologias engessadas, ou seja, formatos que servem para ensinar a todos de uma mesma forma, baseados em posturas tradicionais de ensino. Alguns educadores não escutam a gestão e nem dão atenção aos treinamentos por se acharem conhecedores de causa. Essas metodologias acabam que levando os alunos a perderem o interesse em aprender, pois são conscientes de que também serão cobrados de forma tradicional, com provas exaustivas e que não apresentam situação-problema.

\subsection{Processos de conselho escolar: contribuições para o rendimento dos educandos}

\begin{tabular}{|l|l|}
\hline \multicolumn{2}{|c|}{ Categorias conceituais de análise } \\
\hline $\begin{array}{l}\text { Objetivo 3: Compreender como ocorre o processo do conselho escolar na escola e } \\
\text { sua contribuição para o rendimento dos educandos }\end{array}$ \\
\hline $\mathbf{0 1}$ & $\begin{array}{l}\text { Formato de reuniões que não contribui para uma discussão aprofundada dos } \\
\text { alunos }\end{array}$ \\
\hline $\mathbf{0 2}$ & O problema sempre está no aluno \\
\hline $\mathbf{0 3}$ & Reflexão sobre a prática como ação de poucos \\
\hline $\mathbf{0 4}$ & O foco no cotidiano do aluno não é visto com bons olhos \\
\hline
\end{tabular}

Educação, Psicologia e Interfaces, Volume 4, Número 1, p. 76-91, Janeiro/Março, 2020.

ISSN: 2594-5343. DOI: https://doi.org/10.37444/issn-2594-5343.v4i1.220 
Ao focar nesse objetivo, percebeu-se que a reunião, no formato de vinte a trinta minutos por série e com professores tendo que se preocupar com as aulas em outras turmas acontecendo concomitantemente, não colabora para se perceber o aluno e suas individualidades para daí sugerir intervenções. Predominam debates fragmentados e vazios, o que leva os professores a acreditar que o problema de aprendizagem está exclusivamente no aluno, na sua falta de interesse, abstendo-se, como educador, de repensar sua ação educativa; pois crê que já usou todos os procedimentos necessários para facilitar a aprendizagem em sala de aula. Desse modo, muitos creem que o cotidiano do aluno não tem relevância, ao contrário de seus discursos, mas sim a aplicação de metodologias ultrapassadas.

3.6 A ação docente e discente e suas interrelações no ambiente de sala de aula com o fracasso escolar

\begin{tabular}{|l|l|}
\hline \multicolumn{2}{|c|}{ Categorias conceituais de análise } \\
\hline $\begin{array}{l}\text { Objetivo 4: Relacionar a ação docente e discente e suas interrelações no ambiente da } \\
\text { sala de aula com o fracasso escolar. }\end{array}$ \\
\hline $\mathbf{0 1}$ & Métodos repetitivos de avaliação \\
\hline $\mathbf{0 2}$ & Uso do livro didático \\
\hline $\mathbf{0 3}$ & Gestores presentes \\
\hline $\mathbf{0 4}$ & Percepção da necessidade de mudança \\
\hline
\end{tabular}

É comum, em sala de aula, avaliar os alunos de níveis diferentes utilizando os mesmos métodos, alegando que todos são capazes de seguir o mesmo ritmo. Na EEM Adolfo Caminha, não é diferente. Muitas vezes, o professor se vê obrigado a utilizar metodologias arcaicas e sem significados devido a uma estrutura educacional estadual defasada, pautada em um sistema opressor e massificante. Com salas de aula superlotadas, os educadores tendem a otimizar o tempo com o uso do livro didático e exercícios na lousa, sem poder perceber e atender às demandas de dificuldades apresentadas pelos educandos. Nesse aspecto, acabam encontrando justificativas para metodologias "engessadas", fechando os olhos à mudança de perspectivas sobre o aluno, deixando de percebê-lo singular e coletivo.

Pelo que foi observado na atuação dos gestores junto a sala de aula, percebeu-se que seguem o pensamento de Carl Rogers (1997), que se ocupou em perceber o processo educativo atendendo à sua integralidade, na ideia de conhecê-lo e prepará-lo para relacionar-se com seu meio social. Isso, implicou em outros momentos, pois percebendo 
o aluno como centro do processo educacional, a gestão procurou incentivar os professores a fazer parte dessa mesma proposta, através do incentivo ao inusitado, à preparação para se enxergar o chão da escola, considerado um espaço cheio de condições e organizado para favorecer a aprendizagem dos alunos.

Alguns educadores, especialmente das áreas de Linguagens e Humanas, percebiam essa necessidade de mudança e agarraram-se à proposta evidenciando em suas ações o aprendente como constructo de sua relação consigo e com sua realidade social, oferecendo uma sala de aula na qual a promoção do conhecimento começava no momento em que o aluno era visto em sua evolução permanente, um sujeito-ator, que se autoavalia em meio à situação-problema a ele apresentada, atuando como indivíduo participativo, desafiador, instigado a estabelecer relações e intercambiar a aprendizagem.

\section{CONSIDERAÇÕES FINAIS}

Numa sociedade em que as bases sociais estão cada vez mais defasadas, o ser humano tende a evoluir como forma de vencer os desafios da cotidianidade. Por isso, é importante retomar o problema apresentado na pesquisa: Quais os fatores que contribuem para o crescimento da crise educacional contemporânea ligada ao fracasso escolar na EEM Adolfo Caminha, Aracati-CE?

Tendo essa questão como foco, conclui-se que o corpo escolar da instituição investigada deve buscar entender o educando como centro da engrenagem educativa, pois ele é o motivo pelo qual a escola existe. Para isso, deve focar nos fatores que interferem no funcionamento desse engrenagem, tais como, a realidade violenta dos alunos que passa pelo uso de drogas fortes e problemas econômicos que desestruturam famílias e levamnas à desesperança por um futuro melhor, ultrapassando seus muros num contato permanente com a sociedade; a quebra de metodologias educativas engessadas nascidas da falta de compromisso e reflexão sobre a própria prática por parte dos educadores; o desinteresse dos alunos; processos avaliativos antiquados e a má estrutura da reunião de conselho de classe que pouco contribui para a criação de intervenções que visem superar o fracasso escolar.

Educação, Psicologia e Interfaces, Volume 4, Número 1, p. 76-91, Janeiro/Março, 2020.

ISSN: 2594-5343. DOI: https://doi.org/10.37444/issn-2594-5343.v4i1.220 
Este estudo exige um maior aprofundamento, visto que, por sua perspectiva abrangente, pode ser analisado em muitas outras especificidades podendo suscitar novas pesquisas com contribuições significativas para a entidade investigada.

\section{REFERÊNCIAS BIBLIOGRÁFICAS}

ASSOLINI, F. E. P. Pedagogia da leitura parafrástica. Dissertação de Mestrado nãopublicada, Universidade de São Paulo, Ribeirão Preto, SP. 1999.

AUSUBEL, D. P; NOVAK, J.D; H. Educational Psychology: a cognitive view. 2 ed., New York, Hat Rinehart and Winston, 1978.

CHARLOT, B. Da relação com o saber: elementos para uma teoria / trad. Bruno Magne, Porto Alegre: Artes Médicas Sul, 2000.

COSTA, L. C. A.; NASCIMENTO, J.V. O ensino da técnica e da tática: Novas abordagens metodológicas. Revista de Educação Física/UEM. Maringá, v. 15, n. 2, 2004.

FREIRE, P. Pedagogia da autonomia: saberes necessários à prática educativa / Paulo Freire. - São Paulo: Paz e Terra, 1996, (Coleção Leitura).

MEDEIROS, C. P. (2003). A disciplina escolar: A (in)disciplina do desejo. In: ABRAMOWICZ, A.; MOLL, J. (Orgs.) Para além do fracasso escolar. 6 ed. Campinas, SP: Papirus.

PAULA, F. S.; TFOUNI, L. V. A persistência do fracasso escolar: desigualdade e ideologia. Revista Brasileira de Orientação Profissional, 2009, 10(2), pp. 117-127.

PIMENTA, S. G. Formação de professores: identidade e saberes da docência. In: PIMENTA, S. G (org.). Saberes pedagógicos e atividade docente. 3 ed., - São Paulo: Cortez, 2002, p. 15-34.

REY, G. F. Pesquisa qualitativa e subjetividade: Os processos de construção da informação. Trad. SILVA. M. A. F. São Paulo: Pioneira Thomson Learning, 2005.

RINK, J. E.; FRENCH, K. E.; TJEERDSMA, B. L. Foundations for the Learning and Instruction of Sport and Games. Journal of Teaching in Physical Education, v. 15, n., p. 399-417, 1996.

ROGERS, C. R. Tornar-se pessoa. 5 ed., - São Paulo: Martins Fontes, 1997.

SAMPIERI, R. H.; FERNÁNDEZ-COLLADO, C.; LUCIO, P. B. Metodologia de la investigación. México: McGraw, 2006.

SAVIANI, D. Escola e democracia. 36.ed. Campinas: Autores Associados, 2003.

\section{Credenciais da/os autora/es}

Educação, Psicologia e Interfaces, Volume 4, Número 1, p. 76-91, Janeiro/Março, 2020.

ISSN: 2594-5343. DOI: https://doi.org/10.37444/issn-2594-5343.v4i1.220 
SILVA, Renildo Franco da. Professor dos cursos de Letras e Pedagogia da Faculdade do Vale do Jaguaribe, graduado em Letras (FVJ), Mestre Educação (EFRJ). E-mail: renildo.franco@gmail.com

Endereço para correspondência: Renildo Franco da Silva. Rua: Francisco de Assis Nogueira, n. 281, Bairro: Campo Sâo Francisco CEP: 62800000, Aracati/Ceará. E-mail: renildo.franco@gmail.com

\section{Como citar este artigo (Formato ABNT):}

SILVA, Renildo Franco da. Fracasso escolar: um estudo de caso da crise educacional contemporânea em Aracati-CE. Educação, Psicologia e Interfaces, v. 4, n.1, p. 76-91, 2020. DOI: https://doi.org/10.37444/issn-2594-5343.v4i1.220

Recebido: 07/08/2019.

Aceito: 20/11/2019. 